\title{
Analysis and Assessment Method for Fluctuation Characteristics of Daily Solar Resources Concerning on PV Output Requirements
}

\author{
Qiao Sun ${ }^{1, a}$, Ling $\mathrm{Nie}^{1, \mathrm{~b}}, \mathrm{Xu} \mathrm{Li}^{2, \mathrm{c}}$, Jianxi $\mathrm{Yao}^{2, \mathrm{~d}}$ and Honglu $\mathrm{Zhu}^{2, \mathrm{e}}$ \\ ${ }^{1}$ Beijing Guodiantong Network Technology Co., Beijing 100070, China; \\ ${ }^{2}$ School of Renewable Energy, North China Electric Power University, Beijing 102206, China. \\ a sunqiao@sgepri.sgcc.com.cn, b nieling@sgepri.sgcc.com.cn, ${ }^{\mathrm{c}}$ lixu_ncepu@126.com, ${ }^{\mathrm{d}}$ \\ jianxiyao@ncepu.edu.cn, ${ }^{\mathrm{e}}$ hongluzhu@126.com
}

Keywords: daily solar resources, PV output, fluctuation characteristics.

\begin{abstract}
Solar resources assessment is one of the basic works for planning and construction of PV station. Conventional method of solar resources assessment cannot meet the rules made by China's power section to limit the output power fluctuation of PV connected to grid. This paper proposes a method to evaluate fluctuation characteristics of daily solar resources, with theoretical solar irradiance was introduced as a reference for observed irradiance. Cumulative feature of daily solar resources under four typical weather conditions were analyzed. Result shows that method proposed in this paper can comprehensively reflect fluctuation characteristics of daily solar resources and has certain reference significance for planning and designing of PV.
\end{abstract}

\section{Introduction}

China is rich in solar resources, whose theoretical reserve reaches 1700 t standard coal annually. Daily irradiation in most regions of China exceeds $4 \mathrm{kWh}$ per square meter and the annually sunshine duration is greater than 2000h. Conventional solar resource assessment methods in China usually evaluated richness degree and stability degree of solar resource where PV power station plans to be built, based on solar resource standards[1]. However, conventional solar resource assessment method with historical meteorological observation data use global horizontal irradiance in time scales of month and year to analyze the feature of solar resources, which cannot meet the requirement from power industry to analyze the fluctuation of solar resource in high-frequency like $15 \mathrm{~min}$ or more. To meet the demand of more and more PV power stations connecting to grid, China Electricity Council proposes standard GB/T 19964-2012 Technical requirement for connecting photovoltaic power station to power system, which stipulates that active power change rate of PV power stations in 1-min should not exceed $10 \%$ of installed capacity [2]. Therefore, it is reasonable to analyze solar resource based on 24h time period and minutes time resolution, which could meet the requirements of power industry to PV power station.

Irradiance variability can be defined and calculated in many different ways. The easiest method is to calculate the standard deviation of the time series data. Another method to characterize irradiance variability is to measure some special parameter[3-5]. But the above method can not comprehensively reflect the fluctuation rate and accumulated fluctuations of daily solar resources. In this paper, degree of fluctuation of daily solar resource is described with fluctuation cumulative parameter $\left(F_{\text {cum }}\right)$.

This paper is organized as follows: the second section explains conventional solar resource assessment method and power system connection requirements of China's electricity industry to PV power station. Besides, observed data of solar energy resource in Beijing was analyzed to illustrate the characteristic of solar resource in Beijing. In the third section, a new method to evaluate stability of solar resource in period of day is proposed. Finally, calculation and analysis results of variability in daily solar resource under four typical weather conditions are provided in the fourth section. All observed solar irradiation data in this paper are from meteorological station of North China Electric Power University $\left(40.089^{\circ} \mathrm{N}, 116.306^{\circ} \mathrm{E}\right)$. 


\section{Requirements for Fluctuation of Active Power Output}

\subsection{Conventional Solar Resource Assessment.}

Meteorological industrial standard QX/T 89-2008 Assessment method for solar energy resources issued by China's Meteorological Administration offers the definition of solar resources. Richness level of solar resources is assessed by the indicator of annual total amount of global horizontal irradiation[1]. The stability of solar resource is often calculated by the quotient of the maximum value and minimum value of days when sunshine duration is greater than $6 \mathrm{~h}$ in each month within one year, as shown in equation (1).

$$
K=\frac{\max \left(\text { Day }_{1}, \text { Day }_{2}, \cdots \text { Day }_{12}\right)}{\min \left(\text { Day }_{1}, \text { Day }_{2}, \cdots \text { Day }_{12}\right)}
$$

Where, $K$ is stability indicator of solar resource and is a non-dimensional number; $D y_{1}$, Day $_{2}, \cdots$ Day $_{12}$ means the number of days when sunshine duration exceeds $6 \mathrm{~h}$ in each month from January to December, with the unit of day (d).

\subsection{Requirements for PV Connecting Grid.}

PV power generation is one of main forms of solar power generation. China's national and corporate standards [2, 6] put forward requirements for the fluctuation of active power output of grid-connected PV power stations. As for PV power stations integrated to grid through $35 \mathrm{kV}$ and above voltage grade, as well as newly-built, transformed and expanded PV power stations connected to public power grid through $10 \mathrm{kV}$ voltage grade, GB/T 19964-2012 Technical requirement for connecting photovoltaic power station to power system proposes that the change rate of active output power of PV power stations shall not exceed 10\% of installed capacity[2]. Q/GDW 617-2011 Technical rule for photovoltaic power station connected to Power Grid issued by State Grid Corporation of China puts forward regulation of active power change for different scales of PV power stations, as shown in Table 1. Therefore, understanding output power change rate and fluctuation level of PV power stations is of great practical engineering significance for PV power station to connect power grid.

Table 1 Limit of maximum active power change for PV power station(Note: The output power drop of PV power station caused by the rapid decrease in solar irradiance is subject to the above restrictions.)

\begin{tabular}{|c|c|c|c|}
\hline Station scale & $\begin{array}{c}\text { Voltage } \\
\text { grade }\end{array}$ & $\begin{array}{l}\text { Maximum active power } \\
\text { change at } 10 \text { minutes } \\
\text { intervals ( MW })\end{array}$ & $\begin{array}{l}\text { Maximum active power } \\
\text { change at } 1 \text { minute } \\
\text { interval (MW) }\end{array}$ \\
\hline small & $380 \mathrm{~V}$ & Capacity & Capacity /5 \\
\hline Intermediate & $10 \mathrm{kV} \sim 35 \mathrm{kV}$ & Capacity & Capacity /5 \\
\hline large & $\geqslant 66 \mathrm{kV}$ & Capacity /3 & Capacity /10 \\
\hline
\end{tabular}

\subsection{Fluctuation of Daily Solar Irradiation.}

Curves of daily global horizontal solar irradiance under four typical weather conditions (clear, cloudy, overcast, rainy) are shown in Fig.1, where the solid line represents observed solar irradiance; imaginary line represents the theoretical solar irradiance on that day; four colours correspond to four seasons. It is known from Fig. 1 that, under four typical weather conditions (clear, cloudy, overcast, rainy), curves of daily global horizontal solar irradiance have respective features. Under the cloudy and rainy days, changes in daily irradiance are violent, and change rate is fast. Taking observed solar irradiance in spring as an example, shown in Fig. 1(b) and (d). The maximum increased or reduced values of observed solar irradiance within 1 min reach $492 \mathrm{~W} / \mathrm{m} 2$ and $416 \mathrm{~W} / \mathrm{m}^{2}$, respectively. The maximum change value of active output power of PV power station in 1 min affected by solar irradiance may exceed $40 \%$ of installed capacity, which exceeds the threshold limit represented in Table 1. This will impose great impacts on safe operation of power grid.

The output of PV power station is directly influenced by solar irradiance. The fluctuation of solar irradiance is a significant factor for PV output changes. Fluctuations of solar irradiance directly reflect the variations of PV output, so it is scientific and reasonable to carry out analysis and evaluation of PV output through in an indirectly way by using solar irradiance. It is known from the above requirements that relevant standards of electrical power industry in China need to detect the 
fluctuation of solar irradiance in time period of $1 \mathrm{~min}$ or $10 \mathrm{~min}$. While in meteorological industrial standard, the stability level is analyzed in time period of year, which means characteristics of solar irradiance fluctuations within one day cannot be analyzed. Thus, analysis and investigation requirements of the above standard cannot be met. Hence, a new method for solar resource evaluation as required is needed.
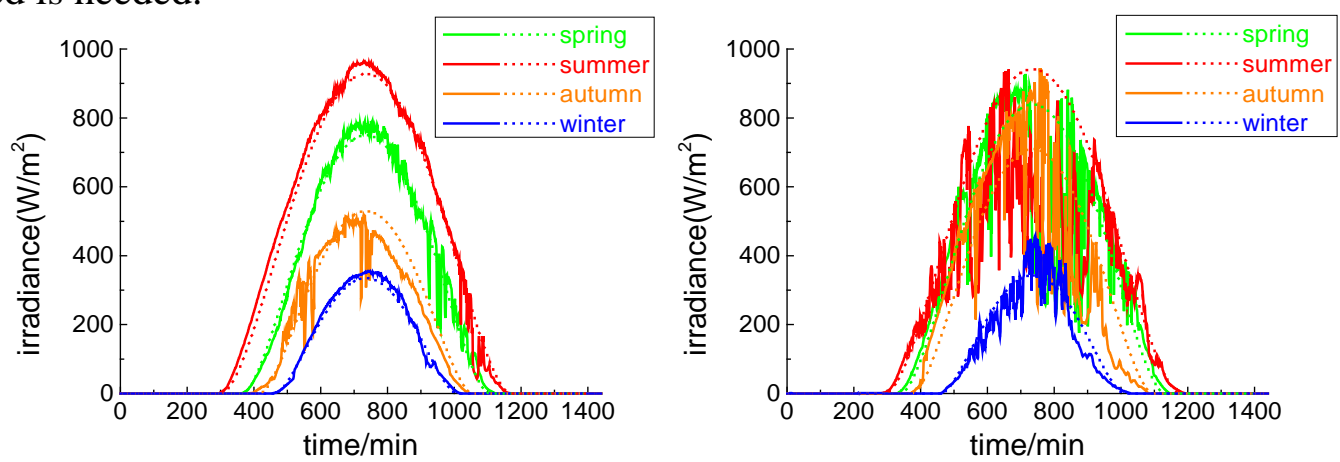

(a) Clear

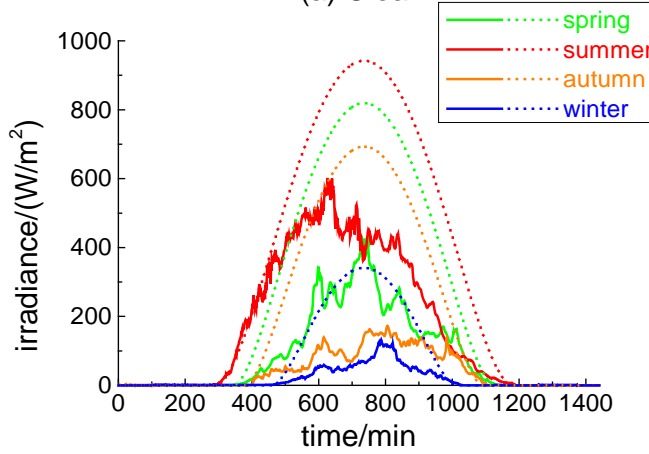

(c) Overcast

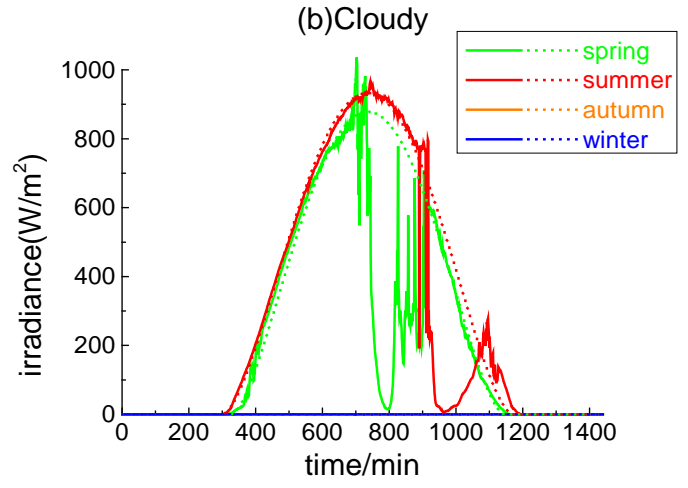

(d) Rainy

Fig. 1 Daily solar global horizontal irradiance in four typical weather conditions

\section{Assessment Method of Fluctuation of Daily Solar Irradiance}

\subsection{Calculation of Theoretical Solar Irradiance.}

Solar resource owns day-based periodicity and non-stability feature due to the effects of cloud layer and meteorological factor. But, without considering the effects of cloud layer and meteorological factor, solar irradiance at any point and any time on the earth surface can be expressed with theoretical irradiance. Theoretical solar irradiance at any time on the earth surface can be gained through calculating such parameters as solar altitude angle, hour angle, declination angle, extraterrestrial solar irradiance, atmospheric optical mass and atmospheric transparency. Theoretical global horizontal irradiance $(T)$ reaching the horizontal plane is shown in equation (2):

$$
T(i)=E_{0} \times \sin h \times\left\{\tau_{b} \times k_{1}+\frac{1}{2} \times \frac{1-\tau_{d}}{1-1.4 \ln \left[\tau_{d} / m(z, h)\right]} \times k_{2}\right\}
$$

Where, $i$ is time or sampling point; $E_{0}$ is extraterrestrial solar irradiance; $\tau_{b}$ is atmospheric transparency factor of direct normal irradiance; $\sin h$ is solar altitude angle; $\tau_{d}$ is atmospheric transparency factor of diffuse horizontal irradiance; $m(z, h)$ is atmospheric optical mass; $k_{1}$ and $k_{2}$ is the factor related to atmospheric turbidity.

In the follow-up researches, theoretical solar irradiance will be introduced as basis reference, which can be convenient for horizontal comparison of solar resource in different seasons and diverse regions.

\subsection{Fluctuation Cumulative Parameter of Daily Solar Irradiance.}

Accumulation characteristic of Fluctuation in daily solar irradiance in one-day time scale can be described with daily accumulation amount of deviation between observed solar irradiance and theoretical value. While statistical method is not suitable for the periodic nonlinear and non-stationary characteristic owned by solar irradiance. Hence, fluctuation cumulative parameter 
$F_{\text {cum }}$ was introduced, whose calculation equation is shown in equation (3). The value of $F_{\text {cum }}$ is between 0 and 1 . When $F_{\text {cum }}$ approaches 0 , this means fluctuation accumulation degree is low; when $F_{\text {cum }}$ approaches 1 , this means fluctuation accumulation degree is high.

$$
F_{\text {cum }}=\frac{\sum_{i=1}^{N}|T(i)-M(i)|}{\sum_{i=1}^{N} T(i)}
$$

Where, $T_{i}$ is theoretical solar irradiance; $M_{i}$ is observed solar irradiance; $i$ is the serial number of sampling point, $i=1,2,3 \cdots N ; N$ is the number of sampling points. In this paper, the sampling period is $15 \mathrm{~min}$. Therefore, there are 96 sampling points within $24 \mathrm{~h}$.

\section{Experimental Section}

Four typical weather conditions (clear, cloudy, overcast, rainy) are chosen from the sample database for further analysis. Fig. 2 shows cumulative feature of daily solar irradiance fluctuation under four typical weather conditions. Fluctuation features of solar resources in Fig.2 under four typical weather conditions are summarized to Table 2.

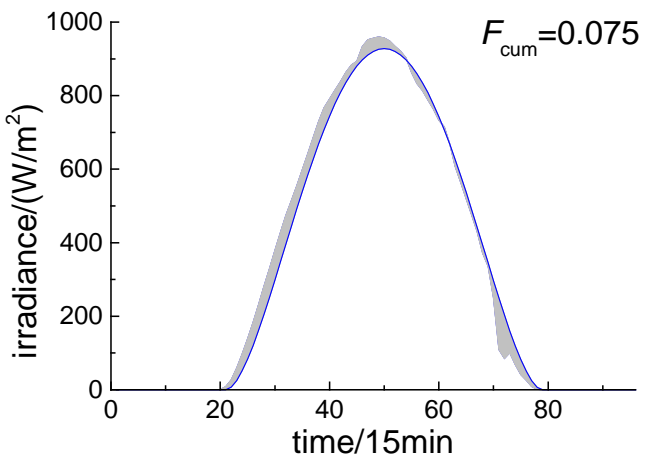

(a) Clear

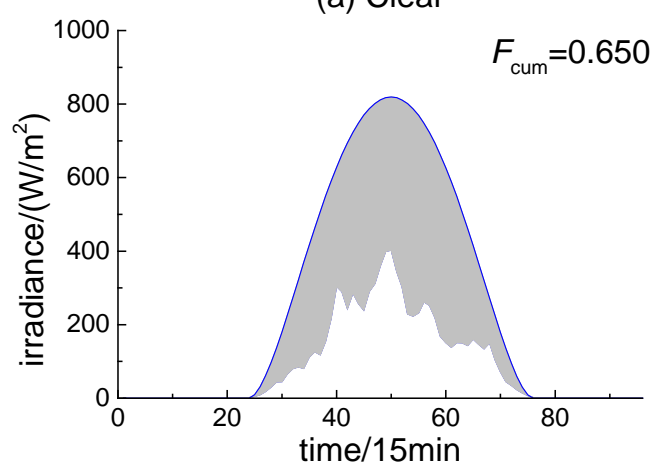

(c) Overcast

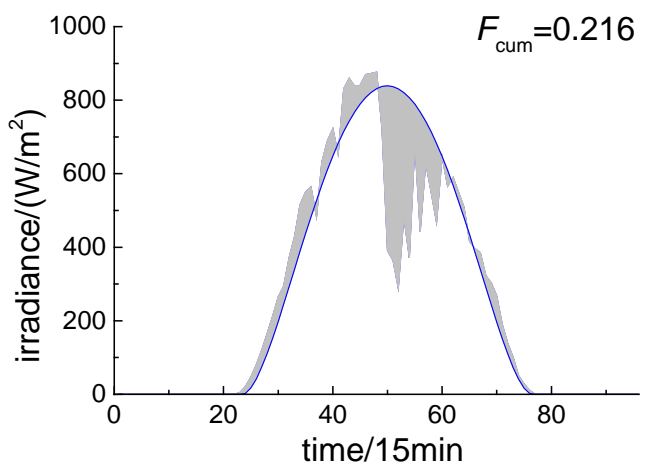

(b) Cloudy

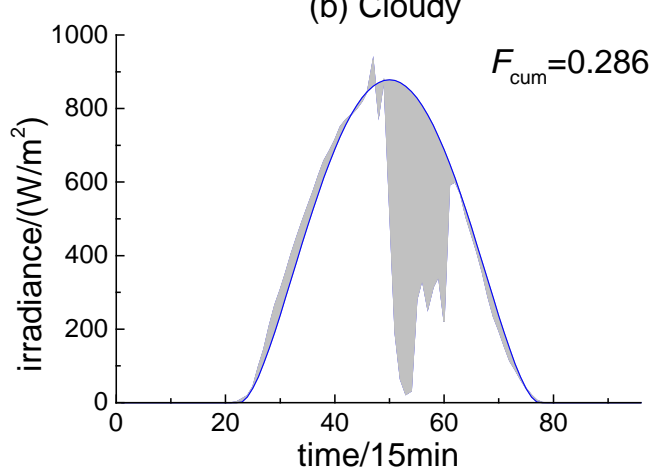

(d) Rainy

Fig. 2 Cumulative feature of fluctuations deviation of daily solar resources under four typical weather conditions

Due to the effects of meteorological environment factors of different types and degrees, fluctuations of daily solar irradiance under four typical weather conditions differ greatly. Detailed information and horizontal comparison are described as follows:

(1) At clear days, time series of observed irradiance and theoretical irradiance have good consistency. The fluctuation cumulative parameter $F_{\text {cum }}$ is least.

(2) At cloudy, overcast and rainy days, time series of observed irradiance has different degrees of volatility. Cloudy days show frequent sharp rise and decrease in a long time period, but its fluctuation cumulative feature is not most significant.

(3) At overcast days, observed solar irradiance is obviously lower than theoretical solar irradiance. Meanwhile, there is low-frequency and low-amplitude fluctuation, which is mild. The daily solar 
global irradiation is least, which is consistent with the fact that fluctuation cumulative parameter $F_{\text {cum }}$ is largest.

(4) Generally speaking, there is rarely pure rainy weather condition in one day, and mixed weather conditions often appeared. Taking thundershower for example, thundershower usually mix with clear days or cloudy days and lasts for several hours in summer. Observed irradiance curve presents $U$ shape, and the lower limit approaches 0. During the occurrence time, low irradiance feature of overcast days is dominated, mingled with low-frequency fluctuation of cloudy days. Meanwhile, the temperature and humidity at front edge time point will change abruptly. Temperature will drop rapidly, and humidity will rise sharply.

Table 2 Fluctuations of daily solar irradiance in four typical weather conditions

\begin{tabular}{cccc}
\hline No & $\begin{array}{c}\text { Weather } \\
\text { condition }\end{array}$ & $\begin{array}{c}\text { Solar global } \\
\text { irradiation } \\
/(\mathrm{kWh} / \mathrm{m} 2)\end{array}$ & $\begin{array}{c}\text { Fluctuations } \\
\text { cumulative parameter } \\
\left(F_{\text {cum }}\right)\end{array}$ \\
\hline 1 & Clear & 7.713 & 0.075 \\
2 & Cloudy & 5.919 & 0.216 \\
3 & Overcast & 2.111 & 0.650 \\
4 & Rainy & 5.307 & 0.286 \\
\hline
\end{tabular}

\section{Conclusions}

According to the requirements of China's power industry for evaluating and analyzing solar resources, an assessment method for fluctuation of daily solar irradiance was proposed in this paper. In order to omit the diversity of solar global irradiation caused by weather conditions, seasons and geographic position, theoretical solar irradiance was introduced as the basis. Fluctuation cumulative parameter $F_{\text {cum }}$ is applied to depict cumulative feature of daily solar resources fluctuation. Example indicates that the method to analyze fluctuations in daily solar resources proposed in this paper can well master features of fluctuation, which satisfy the needs of power industry for solar resource assessment and offer technical analysis means for planning and designing PV power stations.

\section{References}

[1]. Jiangxi Climate Center, Jiangxi Meteorological Bureau. QX/T 89-2008 Assessment method for solar energy resources. China Meteorological Press, Beijing, 2008.

[2]. China Electric Power Research Institute, Institute of Electrical Engineering Chniese Academy Of Sciences, State Grid Electric Power Research Institute. GB/T 19964-2012 Technical requirement for connecting photovoltaic power station to power system. China Electric Power Press, Beijing, 2011.

[3]. S. Harrouni, A. Guessoum, A. Maafi. Classification of daily solar irradiation by fractional analysis of 10-min-means of solar irradiance. Theoretical and Applied Climatology. 80, 1(2004).

[4]. O. Perpiñán, E. Lorenzo. Analysis and synthesis of the variability of irradiance and PV power time series with the wavelet transform. Solar Energy. 85, 1(2011).

[5]. N. Kawasaki, T. Oozeki, K. Otani, et al. An evaluation method of the fluctuation characteristics of photovoltaic systems by using frequency analysis. Solar Energy Materials and Solar Cells. 90, 18-19(2006).

[6]. State Grid Electric Power Research Institute, Institute of Electrical Engineering Chniese Academy Of Sciences. Q/GDW 617-2011 Technical rule for photovoltaic power station connected to Power Grid. China Electric Power Press, Beijing, 2011. 